\title{
Rutas de muerte en la narrativa de Claudia Hernández
}

Hilda Gairaud Ruiz

Escuela de Lenguas Modernas

Universidad de Costa Rica

\begin{abstract}
Resumen
El artículo explora la estética presente en algunas obras de la escritora salvadoreña Claudia Hernández dentro de la literatura de posguerra. Dentro de dicha estética sobresalen las imágenes de violencia y muerte y las marcas que acarrean los cuerpos y las psiques de los personajes que pueden bien vincularse con las vivencias de los salvadoreños durante los procesos de la guerra y la posguerra en El Salvador y la construcción de identidades y subjetividades. Mediante el uso de varios dispositivos literarios, las imágenes muestran las fatídicas marcas de violencia que son el legado de la historia.
\end{abstract}

Palabras claves: muerte, violencia, cuerpos, subjetividad, literatura salvadoreña

\section{Abstract}

This article explores the aesthetics presented in some narratives written by the Salvadorian author Claudia Hernández within the frame of the postwar literature. Images of violence and death and their printings in bodies and psyques dominate the content of her fiction and they illustrate the realities that Salvadorians faced in the context of the civil war and postwar periods. Plot and characters embody how violence in all its expressions has affected the process of construction of subjectivity and has become a legacy of their history.

Key words: death, violence, body, subjectivity, Salvadoran literature 


\section{Introducción}

$\mathrm{E}$ $\mathrm{n}$ este artículo pretendo examinar algunas imágenes y representaciones simbólicas en la narrativa de la escritora salvadoreña Claudia Hernández relacionadas con una estética en donde destaca la muerte dentro de la literatura de posguerra de su país. Las imágenes de muerte, dentro de esta estética, dominan las tramas y el desarrollo de los personajes en los cuentos de la autora, creo que con la intencionalidad discursiva de representar las subjetividades violentadas y las realidades sociales durante los procesos de guerra y posguerra en contexto histórico-social salvadoreño. Mackenbach (2011) señala que el entrecruzamiento entre la historia y la literatura de posguerra es posible puesto que:

Las narraciones y novelas de estos años [a partir de la década de los 1990] se alimentan de diversas relaciones y formas de violencia que caracterizan las configuraciones de las sociedades centroamericanas: la violencia fundacional, justificada estructural e históricamente, rastreable en estas sociedades hasta el acto de violación de la Conquista; las secuelas de la violencia directa, política, y militar de los conflictos armados de las décadas de 1970 hasta 1990 (21).

Aunque Mackenbach (2011:21) advierte que las literaturas centroamericanas no pueden ser entendidas como meras representaciones de realidades centroamericanas por su complejidad, creo que las narraciones como las de Hernández cumplen varias funciones político-sociales: primero, la representación de hechos, que aunque ficticios y simbólicos, no solo tratan de construir la memoria pública del pueblo salvadoreño marcado por la violencia política. Segundo, la narrativa esboza la problematización de la violencia política ante la exposición de la audiencia y su denuncia. Y, por último, en los cuentos puede visibilizarse la representación de las subjetividades afectadas por la violencia en sus contextos: seres humanos carentes, degradados y traumados pero a la vez nobles y necesitados del otro.

La violencia, en todas sus expresiones, marcó el inconsciente colectivo en El Salvador al punto que constituyó una "cultura de violencia" (Candelario, 2004). La representación de la violencia en la narrativa ilustra los tipos de violencia recientemente expuestos por Jan Philipp Reemtsma (2008): la violencia locativa, aquella en donde los cuerpos se expulsan de los espacios que ocupan violentamente; la violencia captiva, en donde los cuerpos son retenidos en contra de la voluntad; la violencia raptiva, cuyas expresiones tienen que ver con la posesión abrupta del cuerpo para fines sexuales y la autotélica en donde la violencia es un fin en sí misma; es decir, cuando se destruye un cuerpo con el único fin de destruirlo. Según Reemtsma (2008), estos tipos de violencia se encuentran en contextos de guerra o en contextos en donde estados centralizados legitiman el ejercicio de la violencia para controlar a los ciudadanos y preservar el orden. El ejercicio de la violencia dentro de este contexto tiene como fin marginalizar o excluir a grupos estigmatizados o minoritarios destruyendo (invisibilizando o aniquilando) a sus miembros víctimas (citado en Baranowski, 2010). 
De manera metafórica y utilizando la ironía y el absurdo, estos tipos de violencia están presentes en la ficción de Hernández, en relatos como "Hechos de un buen ciudadano I y II", Abuelo, y "Manual de un hijo muerto" entre otros. Los cuentos relatan la aparición repentina de cuerpos. Aquí, los cuerpos constituyen una superficie de inscripción de la violencia, un espacio de disputa, un referente a un campo de batalla que lleva inscritas las huellas del combate (García: 2000: 12). Los cuerpos que aparecen corresponden a personajes que han sido secuestrados abruptamente de sus familias de con el fin de desaparecerlos (violencia locativa). Además, el relato insinúa que los cadáveres han sido retenidos (violencia captiva), luego destruidos y abandonados en cualquier parte por quienes quieren obtener poder y "preservar el orden" ilustrando así la violencia (autotélica). De este modo, el objetivo es representar la violencia cuando esta constituye un fin en sí misma.

El referente extraliterario que vincula a estos personajes con la violencia radica precisamente en la historia salvadoreña, en donde un gran porcentaje de la población constituía el blanco de violencia por parte del gobierno y los militares $^{1} \sin$ que esto signifique que estos últimos no hayan estado también expuestos a violaciones. Debido al ultraje violento que sufren algunos personajes en los relatos, es posible entrecruzar sus realidades con la crueldad ejecutada durante los conflictos bélicos. No obstante, a pesar de la transgresión, en algunos casos, estos personajes muestran una necesidad de salir de la opresión y de aspirar y orientarse hacia una vida mejor. Muestran lo que Charles Taylor (1196) describió como un impulso, una "intuición", un marco referencial, hacia lo digno y valioso (43-44). En medio de la transgresión que condiciona la condición existencial de estos personajes, puede notarse un sentido de búsqueda hacia el bienestar.

\section{Los cuerpos violentados}

Las imágenes del cuerpo en la cuentística de Hernández constituyen un recurso literario utilizado para describir los alcances del ejercicio recurrente de diferentes tipos violencia sobre ciertas subjetividades representadas en los personajes. Las imágenes de los cuerpos constituyen,

en el caso de El Salvador [un] espacio, [que] es esencia y conducto de toda manifestación de violencia como el hambre, la desnutrición, epidemias mortales, decapitaciones, desmembramientos, torturas y violaciones que mantienen suspendida en la psiquis colectiva salvadoreña la incertidumbre y el terror (Candelario, 2004).

Las imágenes del cuerpo exponen la violencia autotélica ejercida por quienes cometieron atrocidades para dominar y controlar la población desde los orígenes de la historia salvadoreña. Raúl García (2000) señala que los cuerpos aniquilados durante la Colonia derramaron mucha sangre para desarrollar y afianzar históricamente un sistema basado en desigualdades que luego se impuso al mundo; un 
sistema que promovió una globalización que descansa sobre una gruesa superficie de cadáveres que "hieden" (20). Según García (2000), los agentes dominadores recurren al cuerpo con el fin de apropiarse del control y la dominación ya que los dolores y las afectaciones corporales siempre remiten a un registro (violento) anterior (184-185). En este sentido el cuerpo constituye un geoflifo que lleva las huellas de la violencia (García, 2000, p.12). Es la memoria viva de subjetividades aterrorizadas, mancilladas, abusadas, torturadas, destruidas y descuartizadas que fueron víctimas de la cultura de la violencia.

El cuerpo en los relatos es percibido como un objetivo, un blanco que simbólicamente puede representar a la población que recibió los ataques por parte de grupos en el poder de las fuerzas políticas y militares. En este sentido, Michel Foucault (1984) teoriza sobre el ejercicio de la violencia y la función del cuerpo dentro de este tipo de relación de poder en Vigilar y Castigar:

el cuerpo está directamente inmerso en un campo político; las relaciones de poder operan sobre él [como] una presa inmediata; lo cercan, lo marcan, lo doman, lo someten a suplicio, lo fuerzan a unos trabajos, lo obligan a unas ceremonias, exigen de él unos signos (25).

Las imágenes del cuerpo aparecen en diferentes formas y contextos: hay cuerpos desnudos que evidencian desarraigo y carencia como en "Un hombre desnudo en casa" (Hernández, 2007, p. 27); cuerpos mutilados y descuartizados que remiten al ejercicio brutal de la violencia física, locativa, raptiva y autotélica sobre grupos débiles y volubles, como los niños y los viejos, en relatos como "Manual de un hijo muerto" (Hernández, 2007, p. 105) y "Abuelo" (Hernández, 2007, p. 55). También hay cuerpos mutilados como el del personaje de "Molestias de tener un rinoceronte" en cuyo caso el rinoceronte sustituye el brazo y, además, hay cuerpos muertos que aparecen en cualquier lugar como parte de la cotidianeidad como sucede en "Hechos de un buen ciudadano I y II" (Hernández, 2007, pp. 1537). En todos los cuentos mencionados anteriormente, el cuerpo constituye un territorio simbólico receptor de violencia como parte importante de las rutas y la trayectoria de muerte que procedo a analizar a continuación.

\section{La ruta de los cadáveres}

Para empezar, aunque las imágenes de muerte son constantes en la narración, éstas generalmente aparecen descritas con ironía recurriendo a lo absurdo y están, además, deconstruidas. De esta manera, se establece el tono de la narración: este es percibido como gozoso pero es en realidad macabro. Por ejemplo, la aparición repentina de gran cantidad de cadáveres en algunos de sus relatos constituye una experiencia festiva, una celebración lúdica y, a veces, hasta afortunada, aunque en realidad es un evento macabro. Existe una intencionalidad discursiva en la narración de evocar sentimientos de identificación en el lector con quienes lloran a sus muertos. Podemos entrever un 
deseo de evocar en la audiencia el sufrimiento y la angustia que experimentan los personajes alrededor de los cuerpos y, simultáneamente, de evocar el amor y la ternura hacia ellos.

Lo anterior se muestra en "Hechos de un buen ciudadano II" (Hernández, 2007, p. 39). El narrador es un reclutador de cadáveres que convierte su casa en un cementerio. Para él y para quienes llevan a sus muertos hasta su casa, el encuentro es una ocasión para celebrar festivamente. Ellos se reúnen a tomar té, café, a comer bocadillos y a intercambiar historias, obsequios y alegrías. Complementan la festividad vistiendo los cuerpos al azar: "habían muertas con ropas de hombre, niños con faldas floreadas, jóvenes con indumentarias de ancianos y viejos embutidos en camisas con motivos infantiles" (Hernández, 2007, p. 39). El hecho de que los muertos vistan ropas que no les pertenezcan, sugiere que los cadáveres son de gente desaparecida, sin arraigo ni afiliación social. Es gente común que apareció muerta. Finalmente, como si se tratara de limpiar los remanentes de una fiesta, el narrador limpia, corta, hierve, deshila y ensalza los cadáveres para convertirlos en un soufflé y repartirlos entre los pobres.

El marcador narrativo que sobresale en el relato es el absurdo. De acuerdo con Dorde Cuvardic (2013), el relato simplifica hasta lo absurdo situaciones problemáticas que encarnan los personajes como quien encuentra los cuerpos y quienes corren a buscarlos. Percibir como cotidiana una situación anormal y macabra precisamente expone y resalta lo excepcional de la situación. Además, Cuvardic (2013) manifiesta que la ironía también explica la distribución final de la carne de los cadáveres como alimento y lo ve más bien como una eucaristía. Lo absurdo aquí explica cómo el narrador convierte la tragedia de la muerte de algunos personajes en un acto de redención: "me sentí contento tanto por mí como por los siete cadáveres que habían servido a sus prójimos cuando dijeron que nunca habían tenido mejor cena en la vida” (Hernández, 2007, p. 41). También, con este relato, la narración deconstruye varios valores, creencias y mitos. En primer lugar, la aparición repentina de muertos por doquier no constituye un evento común. Por otro lado, la idea de luto es deconstruida ya que, en vez de seguirse los rituales de muerte, lo que se valora es la profanación. Se distorsiona perversamente la manipulación "correcta" y normal de los cuerpos después de la muerte y se destaca como alternativa una situación absurda.

La narración intensifica el desprecio que los lectores puedan experimentar al imaginar la macabra escena en la trama. Sin embargo, también se devela implícitamente una motivación a la sensibilización que parte del cinismo con que la narración describe los hechos. La presentación de la muerte está casi despojada de su connotación trágica: los cuerpos de los personajes terminan en lo que simbólicamente representan fosas comunes, participan de una "celebración" con ropa inapropiada que no les pertenece y después son cocinados e ingeridos por otros pobres. Con ironía, se sugiere aquí que las situaciones de muerte circunscritas a estos personajes distan de ser "normales" o habituales: no se reclutan cadáveres ni se convierten casas en cementerios, no se celebra la tragedia de muchos, ni se expone a los muertos vistiendo ropas incongruentes con su género y/o edad. Al representar la realidad de la muerte de esta forma, el narrador, 
sarcásticamente, acentúa su significación excepcional, trágica y dolosa, más aún si esta sucede como resultado de la violencia. Es decir, la narración pretende intensificar la desdicha que genera la violencia: el sufrimiento y el desgarramiento que significan primero desaparecer, luego morir violentamente y finalmente encontrar los cuerpos en abandono.

Además, con el uso de la ironía y lo absurdo, la narración resalta la falta de respeto de algunos frente a la memoria de los muertos. Esta falta sugiriere la necesidad de que se instituya en El Salvador una memoria pública de los muertos, que provea a las familias de las víctimas y a la sociedad, la restitución y la reparación que ameritan. El relato sugiere la necesidad que podrían tener las familias de experimentar un sentido de cierre respecto de la búsqueda de los familiares desaparecidos, ya sea que estos estén vivos o muertos. El cierre mitiga el dolor de pensar que ellos fueron secuestrados, torturados, asesinados y abandonados en cualquier parte. En este sentido, Ileana Rodríguez (2012) señala la literatura como un espacio privilegiado que permite experimentar el cierre ya que dentro de él se articula la memoria histórica y la reconstrucción de la identidad nacional en el periodo de posguerra (32).

Roque Dalton (1988) también se había referido a esta problemática de la memoria pública antes de la guerra, justamente cuando recopiló testimonialmente en sus crónicas los hechos de "1932 en 1972 (Homenaje a la mala memoria)", la parte II en el diario El Mundo, en 1972. En este texto, Dalton (1988) relata la captura y matanza de mujeres y jóvenes ladinos y campesinos de la comunidad de Salcoatitán en el año 1932. En la tercera parte del texto "Hechos, cosas y hombres de 1932", "Un testimonio oficial", Dalton (1988, p. 113) describe el ejercicio de la violencia autotélica: el levantamiento de 1931 y el fusilamiento de obreros inocentes, niños, ancianos y mujeres, quienes luego serán cargados en camiones:

cuando la plaza pública estaba repleta de hombres, niños y mujeres pusieron tapadas en las calles de salida de la plaza y ametrallaron a aquellas multitudes inocentes, no dejando vivos ni a los perros que siguen fielmente a sus amos indígenas (115).

La correlación de esta crónica con la historia es ineludible, ya que contiene la ilustración simbólica de la aparición de cadáveres. Según Candelario (2004), el avistamiento de muertos es "parte de la realidad diaria [circunscrita a] eventos que precedieron la guerra y luego la misma guerra". Esta es una realidad que está relacionada con los dominados, puesto que el entorno donde aparecen los muertos es marginal. Es más, los cuerpos se convierten en el alimento de los pobres, vagabundos y pordioseros.

Hay aquí una sugerencia cínica y macabra de cómo se manipularon las muertes de mucha gente durante los eventos trágicos y violentos en la historia de El Salvador. Así lo relata la historia: debido a la guerra y en particular a las acciones de los escuadrones de la muerte se generó un clima generalizado de “desapariciones", matanzas, destrucción y violencia. Eran tantos los cadáveres, 
que cubrían un amplio sector de la población. Todo ello nos lleva a preguntarnos con las situaciones ficticias que relata Hernández: ¿se está sugiriendo que los cadáveres también sirvieron de alimento a otros pobres subalternos?

Esta idea, además, remite a la representación del canibalismo como un hecho redentor. La narración presenta un sacrificio simbólico y con este parece sugerirse que hubo subalternos que fueron sacrificados violentamente. Sus cuerpos aparecieron y luego se convirtieron en el aliento -alimento en el relatopara otros subalternos. El canibalismo remite a los pueblos originarios como por ejemplo los aztecas, quienes sacrificaban víctimas en ofrecimiento a los dioses. En las ceremonias, a las víctimas se les extraía el corazón para luego ofrecer esta sangre a los dioses. Algunas partes del cuerpo, como los brazos y las piernas, se distribuían entre los sacerdotes para su ingesta. Este tipo de ritual era necesario para el buen funcionamiento del Estado y la sociedad puesto que el sacrificio garantizaba el favor de los dioses para el pueblo (Root, 1996, pp. 2-5). Con la colonización y el discurso civilizador y racional yuxtapuesto al religioso, se abolió este tipo de ritual.

En el relato, el canibalismo opera para representar irónicamente el "buen" funcionamiento del sistema social. El texto sugiere en forma cínica que se debe aprovechar la muerte de los subalternos para alimentar con estos mismos cuerpos a los otros subalternos. De esa forma, no solo se resuelve un problema social, ya que los subalternos también ven garantizada la satisfacción de las necesidades básicas -en este caso, el hambre-, sino que también se abre la posibilidad de que se obtengan favores de alguien más. Ahora bien, en este caso no se obtiene el favor de los dioses, sino el de otros sujetos miembros del sistema dominador: estos favores de obtienen gracias a tan "altruistas" actos de conmiseración.

Volviendo a los relatos de Hernández, "Manual del hijo muerto" (2007, p. 107) también resalta la ironía y lo absurdo para deconstruir la realidad de la muerte. La ironía explica el uso de las convenciones genéricas de un manual de instrucciones o de una receta para relatar un hecho atroz (Cuvardic, 2013). El relato expone los tipos de violencia captiva, cuando el niño fue desaparecido; raptiva, porque hay signos de abuso y violencia cuando aparece el cuerpo, y autotéli$c a$, ya que la destrucción del niño no tiene justificación aparente en la narración. La aparición de las partes de un niño desaparecido, muerto y mutilado, recibido "en forma de trozos" (Hernández, 2007, p. 107) y cuyas manos y pies revelan "escenas del padecimiento pre-muerte", es motivo de gozo. Es más, el narrador advierte que es mejor cubrir estas partes del cuerpo con guantes y medias para evitar la "elaboración de hipótesis y encontrar culpables" (109). La reconstrucción del cuerpo de este "niño" sin nombre, quien tiene 24 o 25 años de edad, es motivo de emoción, aún más cuando se sabe que salió completo de la casa de dos a seis días antes. Ahora bien, aunque a esa edad no se es ya un niño, la juventud en los relatos de Hernández es vista como una etapa en la que, en su contexto, se rompe forzosamente la inocencia aunque se esté ya joven. Esto se da porque se vive en medio del horror y la violencia, característicos de un legado de guerra.

Como si fuese un rompecabezas, los miembros del niño deben hilvanarse cuidadosamente: "por lo menos dos centímetros antes de los bordes, para evitar 
que se desgarren las partes cuando se transporte o abrace si ocurre un arrebato de dolor" (Hernández, 2007, p. 108). Con ironía, el narrador recomienda que se preste atención a los miembros ya que podrían haberle entregado los pedazos de un hijo equivocado, en especial al tratarse de las manos y los pies, puesto que "estos suelen - si uno se fija muy bien - revelar escenas de padecimiento" (Hernández, 2007, p. 109).

Estas descripciones, más que evidenciar el gozo de encontrar las partes del niño-hijo torturado, sugieren una motivación a la reflexión: ¿quién pasa por la pena de recibir, coser y ensamblar los cuerpos desmembrados de sus hijos muertos para que parezcan "vivos" y "perfectos"? Solamente quien pretenda narrar los hechos para ahondar en el dolor de la pérdida y la impotencia que trae la muerte. Hay aquí una interpelación a la reacción y a los sentimientos que pueden aflorar frente a la pérdida, la desaparición, el descuartizamiento y la muerte de un niño, pues, ¿qué amenaza puede constituir un infante para otro sujeto? ¿Y por qué se le destruye de esa forma?

En estas interrogantes y en sus posibles respuestas, se plantea una clara denuncia de violación a la vida humana que solo es posible dentro de las relaciones de violencia extrema: hay quienes controlan el poder para situar a otros en desventaja. Quienes descuartizaron al niño están utilizando su cuerpo como una superficie simbólica de su poder donde se inscriben las marcas de la violencia. Hay también un reconocimiento a la memoria de quienes lloran a sus muertos: del horror y del dolor ante la imposibilidad de la restitución de sus niños, hijos y familias. El relato ilustra una relación en donde la violencia actúa directamente sobre los cuerpos: los abate, los desmiembra y los destruye (Foucault, citado en Dreyfus y Rabinow, 2001, p. 257); pero también reconstruye el sufrimiento que genera la violencia.

En este mismo sentido, tanta es la necesidad de revivir a los muertos y/o reconstruir su memoria que el narrador, en el relato "Abuelo" (Hernández, 2007, p. 57), desentierra y luego mutila el cuerpo del abuelo para repartir sus piezas entre los familiares. De esta manera, la narración describe con ironía cómo todos los miembros de la familia pueden tener un "pedazo" del abuelo en sus casas. El texto dice, "busqué la sierra y me dispuse a cortar al abuelo en seis partes, una para cada una de las cinco familias que formaron sus hijos [y] la otra para la abuela, que se decidió por los brazos" (Hernández, 2007, p. 59). Una vez más, la narración deconstruye irónicamente la idea de la muerte y sus rituales sustituyendo el dolor por el gozo. El hecho de mostrar el gozo de contar con alguna pieza del cadáver del abuelo destaca lo absurdo y macabro de la situación y expone, a la vez, la importancia que tiene el amor filial en la narrativa. Traer al abuelo a casa nuevamente significa evocar su memoria. Sin embargo, la felicidad que trae su cuerpo muerto y descuartizado es también dolorosa, precisamente por estar muerto y muerto de esa forma. Hernández deconstruye la realidad: la muerte aparece desposeída de su connotación trágica; la posesión de los pedazos del cuerpo es motivo de alegría. Se trata entonces de una realidad que tiene un significado totalmente inverso. La transgresión de su profanación funciona para mitigar el dolor de su ausencia y a la vez provee una llenura emocional, ya que 
"nada se miraba incompleto con él ahí sentado" (Hernández, 2007, p. 58). Al igual que el niño, el abuelo también representa a las familias fragmentadas y destrozadas que son parte de una sociedad igualmente destruida por el ejercicio legitimado de la violencia autotélica. Además, si se vincula con la historia, las desapariciones de los viejos y, luego, la aparición de sus cadáveres también tienen que ver con los hechos de violencia institucionalizada en El Salvador.

La manipulación de cuerpos y cadáveres así como la violación de todos los rituales y creencias circunscritas a la muerte de un ser humano, sirven en estos relatos para representar la degradación y la violencia que prevalecieron durante el proceso histórico revolucionario salvadoreño. En este sentido, lo que los textos plantean es la necesidad de que se instituya una memoria pública y privada, una remembranza de quienes fueron víctimas de violencia, en este caso, miembros de familias que "perdieron" a sus miembros y luego "encontraron" sus cadáveres. También, esta estética ilustra cómo los eventos de violencia han marcado la identidad, los cuerpos y las psiques a partir de los personajes. Ellos han llegado a creer que sus subjetividades emergen desde la violencia y, por ende, que la violencia constituye la normalidad y su modus vivendi.

A partir de estos relatos, podemos apreciar que los niños y los viejos, dentro de este contexto de aniquilación y destrucción, se convirtieran también en grupos subalternos vulnerables. La exposición frente a acontecimientos sociopolíticos trágicos (García, 2000, p. 11), como la guerra, afectaron y marcaron negativamente la subjetividad de estos grupos, ya que en muchos casos la violencia tuvo como blanco sus cuerpos y psiques. Las huellas de las violaciones y matanzas inscritas en sus mentes destruyeron las presunciones de inocencia e ingenuidad asociadas a la niñez y convirtieron a este sector de la población en el grupo dañado por la guerra. Probablemente, esta generación de niños crezca traumatizada por la guerra.

Sin embargo, los relatos "Manual del hijo muerto" (Hernández, 2007, p.106) y "Abuelo" (Hernández, 2007, p. 56), también ilustran una necesidad de distanciamiento de la violencia. En un nivel personal, esta necesidad la manifiestan los personajes como una fuerza interior que surge para alivianar el sufrimiento y el agobio provocados por la separación, la ausencia y la muerte, sobre todo en los casos del niño y del abuelo. Aunque la narración describe irónicamente la reposición de los cuerpos (uno descuartizado y cosido y el otro desenterrado, desmembrado y repartido), esta reposición macabra de alguna forma manifiesta el amor y restituye el dolor de la ausencia. La presencia de los cuerpos, poder verlos, tocarlos y tenerlos, dan un sentido de cierre a la tragedia de la pérdida.

Es la ausencia del abuelo la que devela los sentimientos de amor de la familia alrededor de él. La narradora lo echa de menos, le hace falta su mirada, su olor y el ruido que generaba su presencia en la casa. Esto se expresa cuando el resto de la familia, al "tropezarse" con el cuerpo que se encontraba muerto desde hacía dos años y tres meses, se emociona y lo abraza durante largo tiempo:

sonreían más de lo que sus labios estaban acostumbrados a hacerlo ... se lanzaron a besarlo y a contarle los últimos sucesos de la familia. Los nietos 
no cesaban de saltar a su alrededor y los hijos no paraban de tocarse el pecho y luego tocarlo a él ... la abuela está transformada. Brillaba. Se había colocado bajo los brazos de él (Hernández, 2007, p. 58).

El amor hacia el abuelo es la fuerza que motiva a la narradora a buscar una sierra y cortarlo en seis partes para que cada familia pudiera llevarse una a su casa. El sufrimiento de la pérdida del abuelo contribuye a resaltar el amor que su familia le tiene, aunque la forma de manifestar el afecto transgreda todos los rituales de muerte. De esta forma, el texto rescata el amor como una fuerza central: irónicamente contrastan el sentimiento y el horror que causan recibir, reconocer y pegar o despegar las partes de un cuerpo. En las instrucciones que aparecen en "Manual del hijo muerto" (Hernández, 2007, p. 107), se advierte con sarcasmo que los padres que reconstruyan al hijo deben tener cuidado durante el proceso. Deben ser cuidadosos al llorar para no humedecer las piezas del cuerpo. Deben tener cuidado con las "variadas manifestaciones de la emoción" ya que estas les pueden impedir reconstruir mentalmente la figura del hijo. La intencionalidad discursiva es la de representar tanto el dolor como el amor. El relato finaliza con la última instrucción: "Llore cada vez que alguien mencione su nombre” (Hernández, 2007, p. 209). La contraposición del amor y el horror interpela nuevamente al lector al evocar el desgarramiento de lo que significa la pérdida de un ser amado. Aquí se ilustran el lamento y la rabia por las condiciones en que murió el niño. El sarcasmo resalta la forma cómo funciona ese sentimiento imperioso del amor ante la ausencia, separación y pérdida de las personas amadas.

La convivencia amorosa entre personajes está truncada por la muerte eventualmente intencional. Lo que resta es lidiar con la carencia y el recuerdo de la destrucción física y emocional. Las familias se ven obligadas a lidiar con una vida defectuosa en donde subyacen la indignación y la aflicción en contraste con el amor. Frente a lo anterior, Fromm (1959) señala que si se tratase del "amor como solución madura al problema de la existencia, este amor significa unión a condición de preservar la propia integridad, la propia individualidad" (31). Por ende, la pérdida del amor conlleva a la destrucción, a la violencia y a la inhumanidad. Las narraciones previamente descritas ilustran la condición aflictiva en que han vivido los personajes subalternos separados violentamente de los seres que aman y de su dignidad e integridad.

Por último, el personaje de Melissa, la protagonista de "Melissa: juegos 1 al 5" (Hernández, 2007, p. 97) es otro ejemplo de la preponderancia que tiene la muerte. Una vez más, el relato mediante la ironía resalta las experiencias de juego macabras de Melissa como si fueran parte de las experiencias cotidianas de la niña. Ella tan solo tiene cuatro años, pero a su temprana edad puede protagonizar las más vívidas y tétricas escenas de muerte. Por ejemplo, en uno de sus juegos ella aparece desnuda "boca abajo, con la lengua entre los dientes y un cinturón del padre que le sale desde la parte más alta de las piernas, donde lo tiene sujeto" (Hernández, 2007, p. 97). Aunque según Melissa se está representando un gato arrollado, la escena bien puede asociarse con la recreación de la experiencia vivida por una víctima de violación. Este juego sugiere que Melissa 
es víctima de violencia raptiva (Reetsma, 2008). En otro juego, ella cae repentinamente a los pies del padre. Se encuentra con los ojos abiertos y clavados en él, simulando ser una paloma muerta por una pedrada. Aquí, figurativamente, la piedra amedranta y trata de aniquilar el símbolo de la paz encarnado en la paloma: la paz ha sido destruida. Pero, quizás, la escena de muerte más representativa, contextualmente hablando, sea la que nos presenta a Melissa jugando con treinta muñecas desnudas y muertas. Las más pequeñas están en gavetas (refrigeradores mortuorios); otras siete se encuentran sobre una sábana para ser atendidas (cama mortuoria). Otras tres, recién llegadas presuntamente de la morgue, están dispuestas en bolsas; cuatro más, listas para que se las lleven los parientes y, las últimas seis, están debajo de la cama porque ya fueron enterradas. Las muñecas todas representan la muerte de niñas en cantidades significativas como un ejemplo sugerente de que ellas fueron víctimas de violencia autotélica; fueron aniquiladas sin un motivo aparente y justificado.

La ironía dilucida cómo los juegos de Melissa son descritos como si fueran parte de la vida cotidiana de una infante, pero en realidad son juegos que representan la mente de una niña marcada por la muerte. Las escenas deconstruyen la idea de la infancia de niños/personajes salvadoreños. Este caso presenta a una niña expuesta a la violencia, a agresiones, a violaciones y a asesinatos: tiene que vivir con los traumas legados de su historia y por eso los proyecta en sus juegos. Los juegos evidencian los graves daños físicos y/o psicológicos legados por eventos o situaciones como las que se viven en las circunstancias bélicas de la guerra (Dickson-Gomez, 2002).

Implícitamente, una vez más, la lectura exhorta al lector a la reflexión y suscita interrogantes como la siguiente: ¿cuántos niños recrean en sus juegos un acto de violación, cuando simulan ser una paloma muerta o convierten sus muñecas en cadáveres en la morgue? Los juegos macabros de la niña reflejan la conducta de una mente enferma. Como lectora, uno reacciona ante la idea de la violencia asociada a la muerte como juego infantil. Esto distorsiona la noción estandarizada de la infancia. No obstante, el relato termina con un gesto de amor: la madre de la niña entra en la habitación, mira alrededor y "le da un abrazo" al lamentarse de haberla llevado a recoger el cadáver de la abuela (Hernández, 2007 , p. 98). Y es entonces cuando aparecen la plasticina, las figuras de animales y de comida que son los "juguetes" que "deberían", dentro de la normalidad, formar parte de los juegos de Melissa. Con el final, el texto enfatiza, en medio de tantas imágenes de muerte, de tragedia y de dolor, la necesidad de rescatar la inocencia.

Como lectora, la propuesta narrativa de Hernández, a partir de la cual se reinscribe la memoria de los personajes muertos en la historia, me permite reconocer mi propia subjetividad y diferenciarla con respecto del otro subalterno en otras realidades. Las narraciones me permiten percibir el dolor extremo generado por la violencia. Al yuxtaponer dentro de mi experiencia la violencia con la paz, me siento interpelada a repulsar el horror de la violencia generada por la guerra y a la vez puedo conmiserarme con las víctimas y sus familias, aunque sea dentro del ámbito de la ficción. La literatura tiene ese cometido: develar 
realidades y verdades desde donde se producen los textos que interpelen, interroguen y reten al lector. Es así porque se trata de la vida de los seres humanos, de su naturaleza y de su condición.

\section{Nota}

1 Reiteradamente he señalado los tipos de violencia y opresión ejercidas sobre las mayorías por parte de los militares durante los conflictos armados. Las expresiones incluyen desapariciones, aniquilamientos, persecuciones, torturas, secuestros, abandono y ejecuciones.

\section{Bibliografía}

Baranowski, Shelley O. (2012). "Violence and Its Denial": The Paradox of Modernity". H-Net Reviews in the Humanities \& Social Sciences. http://www.h-net. org/reviews/showrev.php?id=29802

Candelario, Sheila (2004). Violencia, globalización y literatura: O el dilema del Eterno Retorno en El Salvador. Istmo Revista virtual de estudios literarios y culturales centroamericanos.

Cuvardic, Dorde (2013), asesor de la tesis: Subaltenidad, Exclusión y Violencia: La Construcción de Subjetividades en la Obra Literaria de Claudia Hernández. Sesión de defensa de tesis doctoral presentada por la postulante Hilda Gairaud R. San José: Universidad de Costa Rica.

Dalton, Roque (1998). Las historias prohibidas de Pulgarcito. México: UCA Editores.

Dickson-Gomez, Julia (2002). The Sound of Barking Dogs: violence and Terror among Salvadoran Families in the Postwar. Medical Anthropology Quarterly 16 (4) 415-438.

Dreyfus, H. y Rabinov, P. (2001). Michel Foucault, más allá del estructuralismo y la hermenéutica. Buenos Aires: Nueva Visión.

Foucault, Michel (1984). Vigilar y Castigar: nacimiento de la prisión. México: Siglo Veintiuno.

Fromm, Erich (1956). El arte de amar. Barcelona Ediciones Paidós Ibérica.

García, Raúl (2000). Micropolíticas del cuerpo: de la conquista de América a la última dictadura militar. Buenos Aires: Biblos.

Hernández, Claudia (2007). De Fronteras. Guatemala: Piedra Santa.

Mackenbach, Werner (2011). ¿De la politización a la esteticización? Transformaciones de la violencia y sus representaciones en América Latina. Conferencia impartida en el Simposio "Discursos de violencia y goce en América Latina". Universidad de Costa Rica, 19-20 de setiembre de 2011 (inédita).

Reemtsma, Jan P. (2008). Vertrauen and Gewalt. Versuch uber eine besondere Konstellation der Moderne. Hamburgo: Hamburger Edition.

Rodríguez, Ileana (2010). Estéticas de esperanza, memoria y desencanto: Constitución letrada de los archivos históricos. En: Perversiones de la modernidad. Literaturas, identidades y desplazamientos III. Guatemala: F\&G Editores. 
Root, Deborah (1996). Cannibal culture: art, appropriation, and the commodification of difference. Colorado: Westview Press.

Taylor, Charles (1996). Las fuentes del yo. La construcción de la identidad moderna. México: Paidos. 
